\section{Standardization of Technique in Physical Anthropology}

ONE result of the first International Congress of Anthropological and Ethnological Sciences, held in London in 1934, was the establishment of a permanent International Committee for Standardization of Technique in Physical Anthropology. Miss M. L. Tildesley was elected as chairman, and Prof. H. V. Vallois as secretary, until 1938. The records of the subject have been increasing rapidly in recent years, but it is now generally realized that many of the definitions used are not precise enough to ensure that independent workers will obtain metrical or other descriptions which are truly comparable. The techniques used in measuring living people are the least satisfactory, and in this case the personal equations of observers are large enough to falsify many inter-racial comparisons. Miss Tildesley has been making a grand tour in the interests of her committee, and in January she read a paper, entitled "The Problem of Internationally Standardizing Scientific Method", at the meeting of the Australian and New Zealand Association for the Advancement of Science held in Auckland. This dealt more with organization than with any results as yet achieved. The committee consists of 37 members representing 35 different countries, and it is claimed that the fact that it has no permanent seat is an advantage. Different sections of the work are delegated to small groups, and the members of these will be obliged to collaborate chiefly by correspondence. Resolutions of the committee are to be circulated in French versions, with translations in other languages if this is found necessary. An organization of this kind should bear good fruit, even if its principal achievement should be to persuade those who publish new material to give data which will make it possible to estimate the reliability of their records, such as repeated measurements on the same subjects.

\section{John Buist and the Elementary Bodies of Vaccinia}

In the February issue of the Edinburgh Medical Journal, Dr. Mervyn Gordon directs attention to the work of Dr. John Buist of Edinburgh upon the microscopy of variola and vaccine lymph, which appears to have been lost sight of. In recent years evidence has accumulated that the minute agents of virus diseases such as smallpox, vaccinia and influenza, which are capable of passing through fine filters that stop the passage of ordinary bacteria, are particulate. In fact, it is possible to demonstrate tiny spherical or ovoid bodies in most virus diseases by means of dark-ground illumination, or after suitable staining by ordinary objectives. Their size usually lies between $0 \cdot 1 \mu$ and $0 \cdot 2 \mu$, and they are arranged singly, in pairs, or in groups. These granules have been given the name of 'elementary bodies', and accumulated evidence suggests that they are the causal agent of the virus disease, particularly in vaccinia, in which they are frequently known as "Paschen bodies". In a book published in 1887 ("Vaccinia and Variola : a Study of their LifeHistory"), Buist describes and figures minute bodies which he observed in films of vaceine lymph after prolonged staining with aniline-water gentian violet. Dr. Gordon remarks that there can be little doubt that these bodies described and figured by John Buist (and regarded by him as being the contagium itself) are identical with those afterwards found by Paschen and others and known to-day as the elementary bodies of vaccinia and its causal agent. John Buist was a native of Fife, born in 1846, and was for a time medical superintendent of the smallpox hospital at Barrow-in-Furness. $\mathrm{He}$ died in Edinburgh in 1915.

\section{Natural and Artificial Clouds}

The Symons Memorial Lecture was delivered before the Royal Meteorological Society on March 17, by Prof. D. Brunt, professor of Meteorology in the University of London, on the subject of "Natural and Artificial Clouds". Prof. Brunt pointed out that the motions which occur when an unstable layer of fluid breaks down have been found to be in the form of polygonal prismatic cells, in which the motion at the centre of the cell is upward, when the fluid is a liquid. In air, while the motions in deep layers resemble those in liquids, except that the direction of motion is reversed, the motion in shallow layers made unstable by heating from below consists of a large number of ascending currents, surrounded by much slower descending currents. When the air is bounded at its upper limit by a movable glass plate, the shearing produced by moving this plate will give long rolls extending through the whole length of the chamber, if the upper plate is moved sufficiently rapidly. With slower movements of the upper plate, the chamber is filled with distorted prismatic cells, and with very slow movements of the plate, the chamber is filled with rolls transverse to the direction of motion of the plate. These experimental results can be applied to explain a variety of eloud forms, which are thus presumably in part due to the effects of instability. Among these clouds are those which consist of small cloudlets on a background of blue sky, cloud sheets which show a series of clear holes, and clouds in rolls, which may be analogous to either the longitudinal rolls found in the laboratory with rapid shearing of the top plate, or to the transverse rolls found with slow shearing of the upper plate.

\section{Erosion in the Punjab}

A CONFERENCE held at Simla recently affords evidence that the importance of the erosion question in the outer Punjab Hills is now receiving serious attention. It was presided over by Sir Herbert Emerson, the other members consisting of the revenue member, the financial commissioner for development, three commissioners of divisions, two deputy commissioners, a representative of the Finance Department, a chief engineer of irrigation, the chief conservator of forests, the conservator of the Eastern Circle and the forest research officer. The assembly of so influential a body shows the importance now attached to this problem by Government. Yet the problem is not a new one. For the last four decades it has been discussed, and men 